\title{
Application of Coating Chitosan Film-forming Solution Combined $\beta$-CD-Citral Inclusion Complex on Beef Fillet
}

\author{
HAIJUN CHEN, JIAWEI SHU, PENG LI, BIWEN CHEN, NA LI, LI LI*
}

\author{
Shanghai Engineering Research Center of Aquatic-Product Processing \& Preservation, College of Food Science and Technology, \\ Shanghai Ocean University, Shanghai, China \\ *Corresponding author: L-li@shou.edu.cn
}

Received August 27, 2014; Revised September 19, 2014; Accepted September 24, 2014

\begin{abstract}
This paper reports the effect of combined solution with different antibacterial substance on the total volatile basic nitrogen (TVB-N), total bacterial count (TBC), the sensory properties, $\mathrm{pH}$, the weight loss rate of beef fillets stored at $4 \pm 1^{\circ} \mathrm{C}$. Main components of the solutions were as follows: (A1) Aseptic water, (A2) $1.5 \%(\mathrm{w} / \mathrm{v})$ Chitosan (Ch), (A3) 1.5\% (w/v) Chitosan + 0.5\% (v/v) Citral (CI), (A4) $1.5 \%(\mathrm{w} / \mathrm{v})$ Chitosan $+2.5 \%(\mathrm{w} / \mathrm{v}) \beta-$ Cyclodextrin/Citral inclusion complex ( $\beta$-CD-CI). The A1 group was as the control samples. The beef samples coated Chitosan film-forming solution combined $\beta$-CD-Citral inclusion complex had decreased the total volatile basic nitrogen by $3.0 \mathrm{mg} / 100 \mathrm{~g}$, aerobic bacterial count value was lower by $1.50 \log 10$, the sensory properties was elevated by 10 of total one hundred and $\mathrm{pH}$ value was declined by $0.60 \mathrm{pH}$ units, while the control samples had reached the acceptance limit. Among these four different solutions, the best effect of beef fillet was coated solution of Chitosan combined with $\beta$-Cyclodextrin/Citral inclusion complex, which had prolonged shelf life by approximately 5-7 days.
\end{abstract}

Keywords: chitosan, citral, $\beta$-CD, beef, preservation, inclusion complex

Cite This Article: HAIJUn CHEN, JIAWEI SHU, PENG LI, BIWEN CHEN, NA LI, and LI LI, "Application of Coating Chitosan Film-forming Solution Combined $\beta$-CD-Citral Inclusion Complex on Beef Fillet.” Journal of Food and Nutrition Research, vol. 2, no. 10 (2014): 692-697. doi: 10.12691/jfnr-2-10-7.

\section{Introduction}

Currently, there are mainly two approaches for freshkeeping packaging technology of beef: one is based on packaging techniques, such as modified atmosphere packaging; the other is based on packaging materials, such as finding suitable materials with antibacterial properties [1]. It is necessary to find effective and safe method to elevate the shelf-life of fresh beef.

Beef is a highly perishable food commodity with a rather short shelf life due to microbial activity which is by far the most important cause of spoilage and may be manifested as visible growth, textural changes or off-odors and off-flavors [2]. This situation causes significant economic losses for the beef industry and as consequence the meat industry is looking for effective, natural, preservation methods that provide meat products with extensive shelf life. In addition to traditional methods of dipping or spraying antimicrobial compounds on the food surface, antimicrobial packaging is a promising alternative method to delay food spoilage [3].

Antimicrobial agents can be incorporated into the packaging material, thus limiting or preventing microbial growth [4]. Consumer concerns regarding health and environmental problems have increased demand for additive-free foods; thus, many studies have focused on incorporating natural antimicrobial compounds such as plant essential oils into packaging materials and have achieved gains in protecting foods.

Citral (CI) is the main component of lemon grass oil. It is a naturally occurring isoprenoid with two isomers (geranial and neral), reportedly exerts anti-fungal activity against some citrus postharvest pathogens such as $P$. italicum and Penicillium digitatum, which demonstrated the Citral have anti-bacterial propriety $[5,6,7]$.

The effect of different concentrations of carvacrol [0.1-0.25 $\mu \mathrm{L} / \mathrm{mL}]$ and Citral [0.25-1.5 $\mu \mathrm{L} / \mathrm{mL}]$ was evaluated against Escherichia coli O157: H7 and Listeria monocytogenes at different storage temperatures $\left[8-37^{\circ} \mathrm{C}\right]$ [8], which showed that the Citral have good antibacterial and antifungal activities. However, the application of Citral has been greatly restricted by the properties of low solubility, easily oxidized, volatile [9], which made the Citral not well solute into hydrophilic system. Exploited the Citral as a antibacterial composition need find a delivery system as a vector to help the Citral solute in hydrophilic solution. $\beta$-cyclodextrin $(\beta-C D)$ is cyclic oligosaccharides with a truncated cone shape molecular structure, and $\beta$-CD has unique ability which can form non-covalent host-guest inclusion complexes with variety of molecules including food additives. The $\beta$-CD cavity provides stabilization to protect the guest molecules and prevention of evaporation, degradation and oxidation; in addition, the release rate of the guest molecules can be controlled or delayed by the $\beta-C D$. Therefore, $\beta-C D$ has been widely applied in the fields of chemical segregation 
analysis, medicine, food, and pesticides. [10] Cyclodextrin inclusion complexation is very effective for the stabilization and controlled release of functional additives [11].

Based on the $\beta$-cyclodextrin inclusion Complex of Citral cannot provide integrate packaging material to preserve the beef, it needs substrates. The inclusion complex of Citral and $\beta-C D$ is pulverulent substance which cannot form a package film. In order to exploiting the inclusion complex as the antibacterial agent in packaging film material, It is generally known that the edible material Chitosan is an environmentally friendly packaging material. Chitosan has characteristics of biocompatibility, biodegradable and non-toxic, and antibacterial property. Chitosan has strong inhibitory ability on various bacteria and fungi [12]. Helander [13] proposed that Chitosan can inhibit Gram-negative bacteria because Chitosan interfere the synthesis of the cell membrane, followed by bacterial dissolution and death. It can be applied in the preparation of packaging material in the coating or film because of the properties of filmforming and solubleness. It is suitable for the packaging structure design and food preservation [14].

There are few reports on the method of coating Chitosan film-forming solution combined $\beta$-CD-Citral inclusion complex in the scientific literature. This study provides a available method and a theoretical basis for prolonging the shelf life of fresh beef.

\section{Materials and methods}

\subsection{Materials}

Citral (CI) (purity $\geq 97.0 \%$, food grade), $\beta$-Cyclodextrin ( $\beta$-CD), Glycerol (Gly), Acetic acid, AlkaneC6, Biolog-90 $\mathrm{mm}$, and Sterilized homogenization bags were purchased from Sinopharm Chemical Reagent Co., Ltd. (Shanghai, China); Chitosan (Ch) (40 100 mesh, food grade), Ethanol anhydrous (purity $\geq 99.5 \%$ ), Tween-80, Nutrient agar, and Sodium chloride (purity $\geq 99 \%$ ) were purchased from Sangon Biotech (Shanghai) Co., Ltd. (Shanghai, China); Fresh beef was purchased from Shanghai meat Co., Ltd. (Shanghai, China);

Electric mixing water bath (JB 90-S, specimen model factory, Shanghai, China); PH meter 10 (Sanxin Co., Ltd., Guangxi, China); Kjeltec ${ }^{\mathrm{TM}} 2300$ Analyzer Unit (FOSS Tecator AB, Sweden); Cleanbench (STIK (shanghai) instrument equipment Co., Ltd. China); Bag Mixer, French Interscience Co., Ltd.

\subsection{Preparation of $\beta$-CD-CI Inclusion Complex}

The Citral/ $\beta$-CD inclusion complex ( $\beta$-CD-CI) was prepared by using a co-precipitation method described by Ayala-Zavala et al. with minor modification [15].

The $\beta$-CD (10.0 g), with deionized water 1:10 scale, were placed in a thermostated bath magnetic stirrer (speed at $120 \mathrm{r} / \mathrm{min}$ ) and stirred at $60^{\circ} \mathrm{C}$ for $1 \mathrm{~h}$. The $\beta$-CD completely was dissolved to form clear solution, and then Citral $(1.0 \mathrm{ml})$ was added into the solution drop wise and stirred for $4 \mathrm{~h}$. Afterwards, the solution were preserved at $4^{\circ} \mathrm{C}$ for $24 \mathrm{~h}$. The inclusion compound solution was vacuum filtrated, and washed for three times using ethanol and deionized water (washing away redundant oil, and non-inclusion $\beta$-CD). The inclusion compound powder was dried under vacuum conditions at $45^{\circ} \mathrm{C}$ for $4 \sim 5 \mathrm{~h}$ until constant weight to obtain the inclusion complex of $\beta$-CD with Citral ( $\beta-C D-C I)$.

\subsection{Preparation of the Coating Solution}

The inclusion complex of Citral and $\beta-C D$ was prepared. The specific coating solutions' components were prepared, as follows:

A1: the control (the sterilized water);

A2: Ch 1.5\% (w/v) + Tween-80 0.4\% (v/v) + Gly 1\% (v/v) + Acetic acid 1\% (v/v);

A3: Ch 1.5\% (w/v) + Citral 0.5\% (v/v) + Tween-80 $0.4 \%(\mathrm{v} / \mathrm{v})+$ Gly $1 \%(\mathrm{v} / \mathrm{v})+$ Acetic acid 1\% (v/v);

A4: Ch 1.5\% (w/v) + $\beta$-CD-CI 2.5\% (w/v) + Tween-80 $0.4 \%(\mathrm{v} / \mathrm{v})+$ Gly $1 \%(\mathrm{v} / \mathrm{v})+$ Acetic acid 1\% (v/v);

The solution of A4 was prepared according to the following steps.

Firstly, Chitosan (1.5 g) was dissolved into 1\% acetic acid solution $(100 \mathrm{ml})$ for preparing the $1.5 \%$ Chitosan solution, which need stirring at $60^{\circ} \mathrm{C}$ for about $1 \mathrm{~h}$ until Chitosan was completely dissolved. Secondly, the solution was placed on a magnetic stirrer for keeping constant temperature and stirred speed. And then the plasticizer Glycerol $(1.0 \mathrm{ml})$, at a concentration of $66.7 \%(\mathrm{w} / \mathrm{w}$ Chitosan), and Tween-80 (0.4 ml), at a concentration of 26.7\% (w/w Chitosan), were added to mixed solution, stirred for 30 minutes. Lastly, $\beta$-CD-CI inclusion complex (2.5 g) was added toss the mixed solution, at a concentration of $166.7 \%$ (w/w Chitosan), dissolved and stirred for about $1 \mathrm{~h}$ until homogeneousness. The final antibacterial Chitosan combined solution was prepared.

\subsection{Treatment of Beef Samples}

The beef samples were selected from the fresh beef shank. After slaughtering, the beef was transported to the laboratory from the market within 45 minutes. In the process, ice was used to keep the surrounding temperature at $0-4^{\circ} \mathrm{C}$, and relative humidity was $80 \% \sim 95 \%$. The beef core temperature dropped to $7^{\circ} \mathrm{C}$ or less within $36 \mathrm{~h}$.

Fillets (25 g) were obtained from each beef under $12^{\circ} \mathrm{C}$ conditions. The samples were immersed in different coating solutions, taken out and well drained. Then the samples were airproofed in PE (Poly Ethylene) bags. Each sample was labeled and sealed, in accordance with the coating solution of A1, A2, A3, and A4.

The packaged beef samples were stored in the lab refrigerator at $4 \pm 1^{\circ} \mathrm{C}$ and the relative humidity maintained $80 \% \sim 95 \%$ for 30 days. The $\mathrm{pH}$ values, sensory properties, the weighted loss rate, total bacterial count (TBC) and TVB-N of the beef samples were monitored on day of 0 , 3rd, 7th, 11th, 14th, 17th, 20th, 24th and 27th of storage.

\subsection{Methods}

\subsubsection{Measurements of Fourier Transformed Infrared (FTIR) Spectra}

The FTIR spectra of Citral, $\beta-C D$, physical mixture and the inclusion complex were collected between 4000 and $500 \mathrm{~cm}^{-1}$ (Mid infrared region) on a Nicolet Nexus Avater 370 FTIR spectrophotometer (Nicolet, USA) with 32 
scans at a resolution of $4 \mathrm{~cm}^{-1}$. Citral was recorded on $\mathrm{KBr}$ plates. The physical mixture and the inclusion complex were ground with spectroscopic grade potassium bromide $(\mathrm{KBr})$ powder and then pressed into $1 \mathrm{~mm}$ pellets (2 mg of sample per $200 \mathrm{mg}$ dry $\mathrm{KBr}$ ). A blank $\mathrm{KBr}$ disc was used as background [11].

\subsubsection{Measurements of the Weight Loss Rate}

During storage period, beef sap outflow at vary degrees, which affects the consumer acceptance and product quality. The weight of each sample was recorded before and after the test, the modified method described in Payne et al [16]. The weight loss rate of beef (WLRB) was calculated using the following equation:

$$
\mathrm{WLRB}=\frac{\left(\mathrm{W}_{\text {initial }}-\mathrm{W}_{\text {ultimate }}\right)}{\mathrm{W}_{\text {initial }}} \times 100 \%
$$

$\mathrm{W}_{\text {initial }}$ : refers to the initial weight of the beef;

$\mathrm{W}_{\text {ultimate }}$ : refers to the ultimate weight of the beef.

\subsubsection{Measurements of the $\mathrm{pH}$}

Triplicate $5 \mathrm{~g}$ samples of ground beef were homogenized with $50 \mathrm{ml}$ of demonized water using a Polytron PT 10-35 homogenizer (Kinematica, Luzernerstrasse, Switzerland), and the $\mathrm{pH}$ was determined using an Accumet $50 \mathrm{pH}$ meter (Fisher Scientific, Fairlawn, NJ, USA) [17].

\subsubsection{Measurements of the Sensory Properties}

The method described by Jingyun Duan et al. [18] with minor modification. The samples were evaluated by 10 members experienced. Panelists were asked to evaluate the viscosity, color, flavor, and texture, using a 100-point hedonic scale $(100=$ like extremely and $10=$ dislike extremely). A score of 60 was taken as the lowest limit of acceptability.

\subsubsection{Microbiological Analysis}

The each sample was transferred into sterile homogeneous bags with $225 \mathrm{~mL}$ of $0.85 \% \mathrm{NaCl}$ solution and homogenized. From this dilution, other decimal dilutions were prepared and appropriate gradient were selected to determine the total bacterial count by using the pour plate method described in Duan J [19]. The inoculated plates were incubated at $37^{\circ} \mathrm{C}$ for $24 \mathrm{~h}$ for total bacterial count. All counts were expressed as log10 CFU/g and performed twice.

\subsubsection{Measurements of the Total Volatile Basic Nitrogen (TVB-N)}

Total volatile basic nitrogen (TVB-N) is an important indicator of chemical spoilage. It was determined by distillation after the addition of MgO to homogenized beef sample. The distillate was collected in a flask containing $3 \%$ aqueous solution of boric acid and a mixed indicator of methyl red and methylene blue. Finally, the boric acid solution was titrated with $0.1 \mathrm{~N} \mathrm{HCl}$. The quantity of TVBN in $\mathrm{mg} / 100 \mathrm{~g}$ was calculated from the volume (V) of $\mathrm{HCl}$ added [20].

\subsection{Statistical Analysis}

The obtained data were expressed as the mean \pm standard deviation of triplicate determinations. Data were analyzed by an analysis of variance $(\mathrm{P}<0.05)$ and the means separated by Duncan's multiple range tests. Statistical analysis was performed using the software STATISTICA $6.0[11]$.

\section{Results and Discussion}

\subsection{Fourier Transformed Infrared (FT-IR) Spectra Analysis}

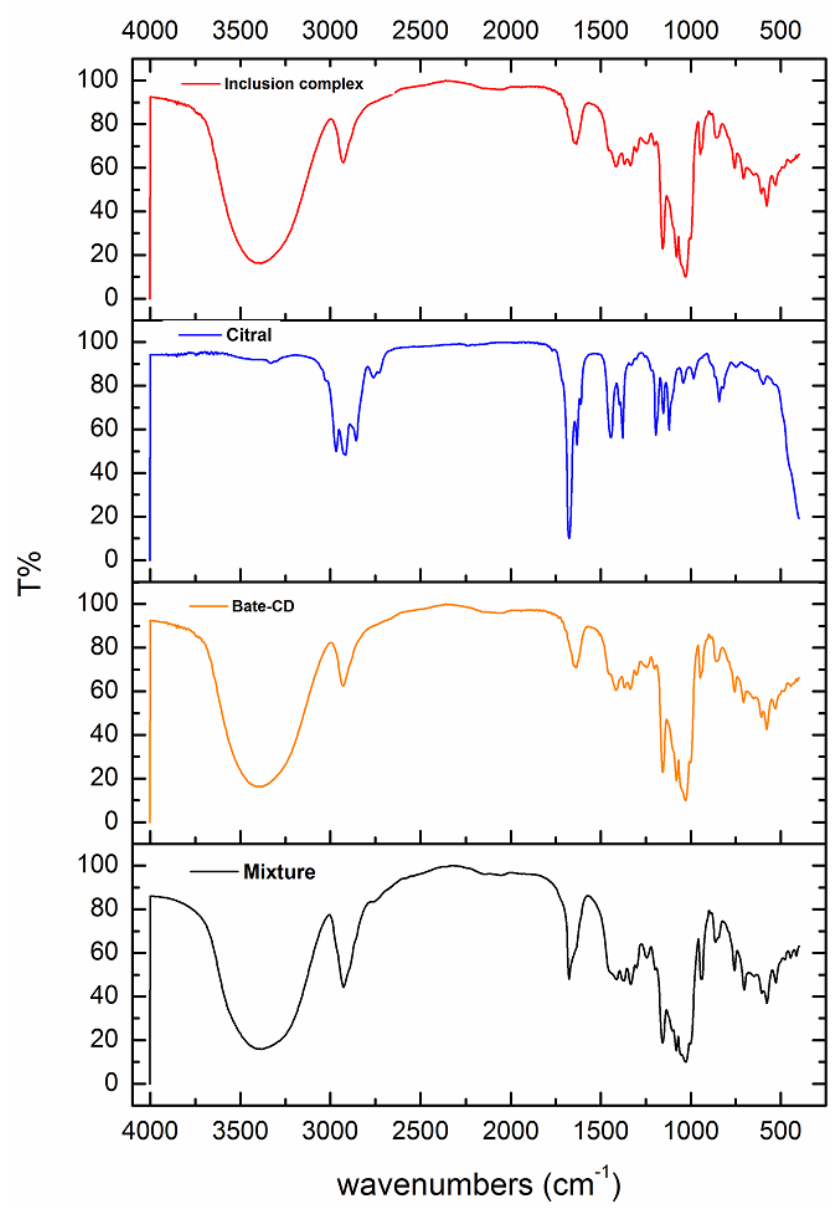

Figure 1. The FTIR spectra of Citral and $\beta$-CD physical mixture, Citral, $\beta$-CD and inclusion complex

Fourier transformed infrared (FT-IR) spectra is used to confirm the information of inclusion complex. The FTIR spectra of Citral, $\beta-C D$, the physical mixture of Citral and $\beta-C D$, and Citral $/ \beta-C D$ inclusion complex are presented in Figure 1. According to the spectrum of Citral/ $\beta-C D$ inclusion complex, the main body cyclodextrin spectra were consistent, but the object of Citral was not detected. This indicated the molecular had been embedded in the cavity of $\beta$-cyclodextrin, which restricted the Citral molecular vibration and hiding its original infrared characteristics [11]. The FR-IT spectrum of $\beta$-CD showed prominent absorption bands at $3384 \mathrm{~cm}^{-1}$ (for O-H stretching vibrations), $2928 \mathrm{~cm}^{-1}$ (for C-H stretching vibrations), $1647 \mathrm{~cm}^{-1}$ (for $\mathrm{H}-\mathrm{O}-\mathrm{H}$ bending), $1156 \mathrm{~cm}^{-1}$ (for C-O stretching vibration) and $1028 \mathrm{~cm}^{-1}$ (C-O-C stretching vibration). The FR-IT spectrum of Citral showed major absorption bands at $1712 \mathrm{~cm}^{-1}$ (for $\mathrm{C}=\mathrm{O}$ stretching vibration) and $2960 \mathrm{~cm}^{-1}$ (for C-H stretching 
vibrations). The band of the inclusion complex exhibits a differential profile compared to the physical mixture, $\beta$ $\mathrm{CD}$ and Citral, suggesting that a kind of link when there is inclusion complex formation The FT-IR spectrum of the physical mixture showed approximate superimposition of the individual patterns of both Citral and $\beta$-CD. However, the FT-IR spectrum of the Citral/ $\beta$-CD inclusion complex showed no feature similar to pure Citral. The bands located at 1712 and $2960 \mathrm{~cm}^{-1}$ of Citral had disappeared. The Citral bands are almost completely obscured by very intense and broad $\beta$-CD bands. However, the absorption bands at $3384 \mathrm{~cm}^{-1}$ and $2928 \mathrm{~cm}^{-1}$ of $\beta-C D$ (Figure 1-C) were shifted toward the lower frequencies at 3310 and $2902 \mathrm{~cm}^{-1}$ of $\mathrm{CI} / \beta-\mathrm{CD}$ (Figure 1-D), respectively. These changes may be related to the formation of intra-molecular hydrogen bonds between Citral and $\beta-C D$.

Table 1. The weight loss rate of beef coated with different solutions

\begin{tabular}{|c|c|c|c|c|c|c|c|c|}
\hline Time (days) & 0 & WLRE(\%) & 3 & WLRE(\%) & 7 & WLRE(\%) & 11 & WLRE(\%) \\
\hline $\mathrm{A}_{1}$ & $25.00 \pm 0.17^{b}$ & 0.00 & $24.99 \pm 0.24^{\mathrm{a}}$ & 0.00 & $24.66 \pm 0.27^{\mathrm{a}}$ & 1.40 & $24.54 \pm 0.30^{\mathrm{a}}$ & 1.80 \\
\hline $\mathrm{A}_{2}$ & $25.00 \pm 0.21^{\mathrm{a}}$ & 0.00 & $24.9 \pm 0.22^{\mathrm{b}}$ & 0.00 & $24.86 \pm 0.16^{\mathrm{c}}$ & 0.60 & $24.76 \pm 0.25^{b}$ & 1.00 \\
\hline $\mathrm{A}_{3}$ & $25.00 \pm 0.15^{b}$ & 0.00 & $24.56 \pm 0.18^{b}$ & 1.80 & $23.94 \pm 0.19^{b}$ & 4.20 & $23.61 \pm 0.27^{\mathrm{a}}$ & 5.60 \\
\hline $\mathrm{A}_{4}$ & $25.00 \pm 0.08^{\mathrm{c}}$ & 0.00 & $24.89 \pm 0.14^{\mathrm{c}}$ & 0.40 & $24.51 \pm 0.23^{b}$ & 2.00 & $24.11 \pm 0.18^{b}$ & 3.60 \\
\hline Time (days) & 14 & WLRE(\%) & 17 & WLRE(\%) & 21 & WLRE(\%) & 24 & WLRE(\%) \\
\hline $\mathrm{A}_{1}$ & $24.46 \pm 0.15^{\mathrm{c}}$ & 2.20 & $24.32 \pm 0.08^{\mathrm{C}}$ & 2.70 & $23.12 \pm 0.21^{b}$ & 7.50 & $23.06 \pm 0.22^{\mathrm{a}}$ & 7.80 \\
\hline $\mathrm{A}_{2}$ & $24.65 \pm 0.12^{\mathrm{c}}$ & 1.40 & $24.57 \pm 0.14^{c}$ & 1.70 & $24.26 \pm 0.23^{\mathrm{a}}$ & 3.00 & $23.91 \pm 0.21^{\mathrm{a}}$ & 4.40 \\
\hline $\mathrm{A}_{3}$ & $23.50 \pm 0.18^{b}$ & 6.00 & $23.02 \pm 0.25^{\mathrm{a}}$ & 7.90 & $22.52 \pm 0.20^{\mathrm{a}}$ & 9.90 & $22.16 \pm 0.10^{c}$ & 11.40 \\
\hline $\mathrm{A}_{4}$ & $23.89 \pm 0.21^{b}$ & 4.40 & $23.25 \pm 0.21^{\mathrm{b}}$ & 7.00 & $23.05 \pm 0.18^{b}$ & 7.80 & $22.81 \pm 0.15^{b}$ & 8.80 \\
\hline
\end{tabular}

a-c:Means in a column, within a treatments group (between treatment groups), not having a common superscript letter are different (P<00.5)

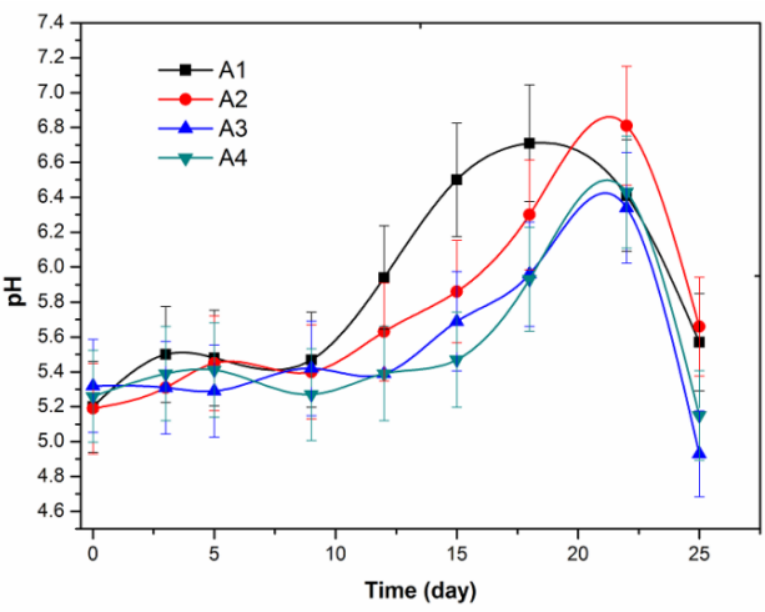

Figure 2. Changes in $\mathrm{pH}$ of beef samples stored at $4^{\circ} \mathrm{C} 3.2$. The Weight Loss Rate

\subsection{The Weight Loss Rate}

The weight loss rate values of the treatments during storage are presented in Table 1 . The beef samples coated with the A2 solution had lowest weight loss rate. The preservation effect of coating A4 solution was better than that of A1. Thus, the weight loss rate had little effect of shelf life of beef samples [16].

\section{3. $\mathrm{pH}$}

After the death of animal, due to respiration of the muscle tissue cells, the body muscle glycogen anaerobic glycolysis and decomposition of ATP, content of lactic acid and phosphoric acid would be increased, resulting in the decreased of $\mathrm{pH}$ value. The $\mathrm{pH}$ value of the fresh meat was about 5.6 to 6.0 . The $\mathrm{pH}$ increasing resulted from producing alkaline substances such as ammonia compounds which caused by action of internal or microbial enzymes, and growth of Gram positive and Gram negative bacteria, yeasts, and molds may also reduce $\mathrm{pH}[21,22,23]$. The $\mathrm{pH}$ values for the treatments during storage are presented in Figure 2. During the storage, the $\mathrm{pH}$ value of the control group significantly increased from 5.20 on Day 0 to 6.71 on Day 18 . Indirectly, the A1 samples began to decay after 11 days, while the A4 sample was began to corrupt in 20 days. The
A4 solution was conducive to prolong the shelf life by 9 days.

\subsection{Sensory Property}

The results of the samples' sensory assessment are given in Figure 3. During the storage, the sensory credit of the control group clearly decreased. The A1 group was lower than 60 scores after 13 days; the A4 samples kept fresh in 21 days and prolonged shelf life by 8 days. The result shows the control group (A1) had beyond the acceptable limit after 13 days, while the A4 group had better shelf life than A1 group.

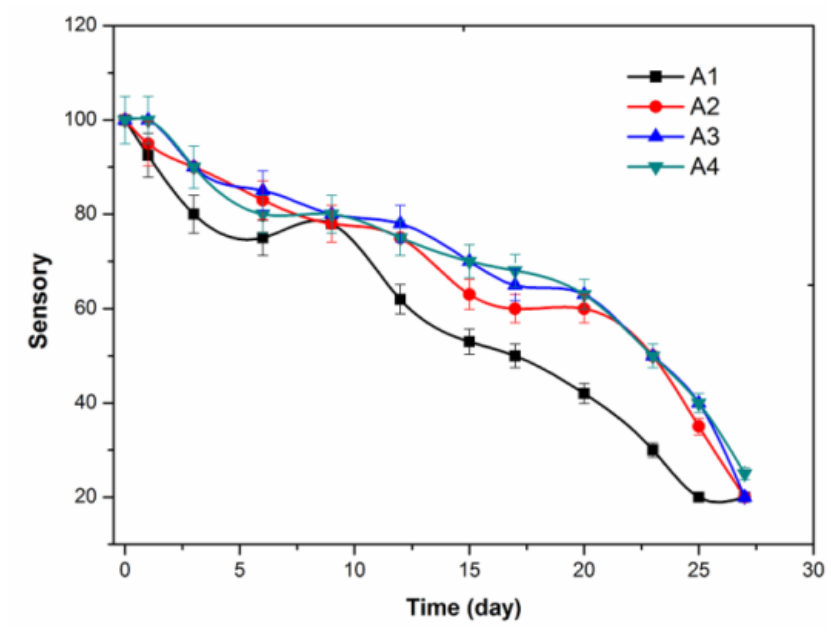

Figure 3. Changes in sensory properties of beef samples stored at $4{ }^{\circ} \mathrm{C}$

\subsection{Microbiological Analysis}

The antimicrobial effect of Chitosan is thought to be related to electrostatic interaction between a positive charge on the NH3 group of glucosamine monomer in Chitosan molecules and negative charge of microbial cell membrane that leads to the leakage of intracellular constituents. The study had regarded $10^{6} \mathrm{CFU} / \mathrm{g}$ as the acceptable limit of meat [19].

Measured changes in total bacterial count during the storage period are shown in Figure 4. The initially total bacterial count of fresh beef samples were 1.52 Log10 CFU/g, and rapidly increased to 3.44 and 6.08 Log10 CFU/g on day 14th and day 24th respectively. The total bacterial count value of A4 samples was lower than other 
groups during the storage. So the coating solution of A4 group was more effective in controlling the microbial growth compared with the other two treatments. The picture shows that, at the same storage shelf life, the A4 samples had lower level of total bacterial count than others groups. It suggested the A4 film-forming solution could retard the decay of beef sample. These results explained by the addition of $\beta$-CD-CI inclusion complex, which conducive to enhance the antibacterial effects and prolong the shelf life of beef fillets.

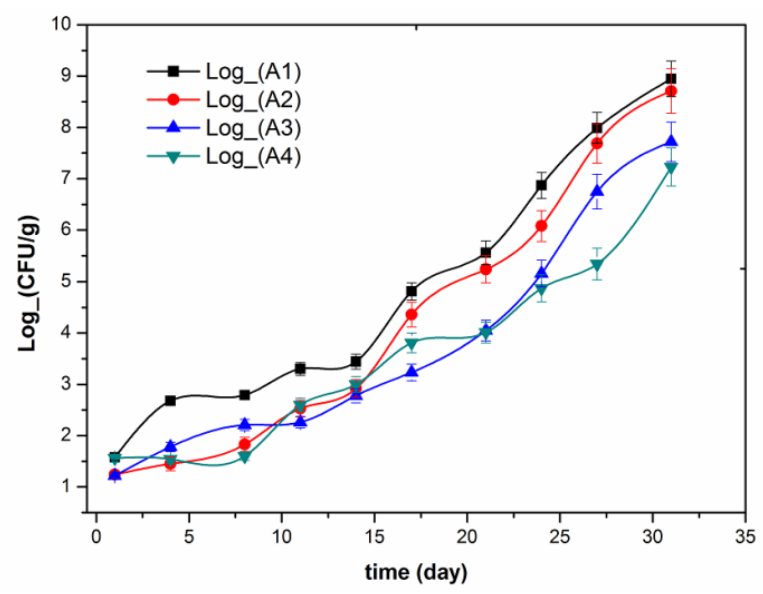

Figure 4. Changes in total bacterial count (TBC) of beef samples stored at $4^{\circ} \mathrm{C}$

\subsection{The Total Volatile Basic Nitrogen (TVB-} N)

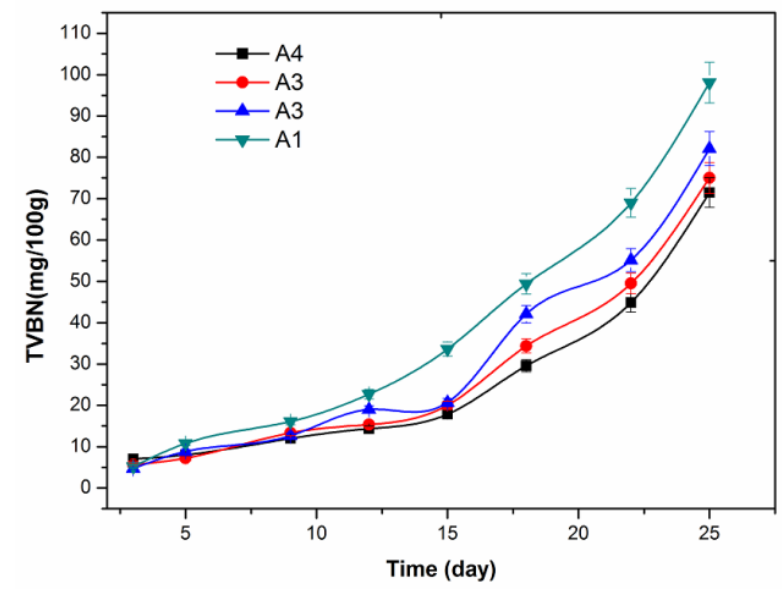

Figure 5. Changes in TVB-N of beef samples stored at $4^{\circ} \mathrm{C}$

The changes in TVB-N values of the beef samples during storage are shown in Figure 5. The initially TVB-N value of the control group was $5.18 \mathrm{mg} \mathrm{N} / 100 \mathrm{~g}$. The values of all treatments increased with varying degrees during storage. TVB-N values of the control group increased to $5.18 \mathrm{mg} \mathrm{N} / 100 \mathrm{~g}$ and $20.56 \mathrm{mg} \mathrm{N} / 100 \mathrm{~g}$ on day 3rd and day 11th; respectively, while the values of samples treated by A4 solution were lower $(p<0.05)$. The addition of Citral deterred further reduction in TVB-N values. TVB-N is widely considered as a quality index of beef, and its increase may be attributed to the activity of spoilage bacteria and endogenous enzymes. Bacterial catabolism of amino acids in beef muscle effected characteristic flavors of beef. Generally, $20 \mathrm{mg}$ TVB$\mathrm{N} / 100 \mathrm{~g}$ of beef is considered as the acceptable limit [20].
At day 13, the A1 group had reached the acceptable limit $20.01 \mathrm{mg} \mathrm{N} / 100 \mathrm{~g}$, while A4 group had reached this level at day 18. In other words, the shelf-life of the control group was only about 13 days; while the beef samples coated the Chitosan solution combined $\beta$-CD-Citral inclusion complex reached limit value at 18 days of storage and prolonged the shelf life by 5 days. The beef samples coated the Chitosan solution combined $\beta$-CDCitral inclusion complex had better effect of prolonging the shelf life than other groups.

\subsection{Summarized evaluation of the Shelf Life}

The indexes of $\mathrm{pH}, \mathrm{TVB}-\mathrm{N}$, sensory properties, and the total bacterial count (TBC) were analyzed by using the summarized evaluation method. The results are shown in Table 2. Briefly, the Chitosan film-forming solution combined $\beta$-CD-CI inclusion complex had best effect on prolonging fresh beef fillets' shelf life.

Table 2. The average shelf life of beef fresh-keeping

\begin{tabular}{ccccc}
\hline Values & A1(days) & A2(days) & A3(days) & A4(days) \\
\hline pH & 12 & 16 & 19 & 20 \\
Sensory & 12 & 15 & 20 & 20 \\
TBC & 22 & 25 & 26 & 27 \\
TVB-N & 13 & 12 & 14 & 18 \\
Average shelf & 14 & 17 & 20 & 21 \\
life (days) & & & &
\end{tabular}

\section{Conclusions}

The analysis results of the $\mathrm{pH}$, total volatile basic nitrogen, the total bacterial count (TBC) and sensory properties showed that, compared with the control group, Chitosan had a good antibacterial effect, and the antibacterial properties of Chitosan combined $\beta$-CD-CI inclusion complex was more excellent, which could inhibit microbial growth and retard spoilage of beef.

The control samples exceeded the acceptable limit of TVB-N on the day 13th, while groups coated solution of Chitosan combined $\beta$-CD-CI inclusion complex reached TVB-N limit on the days 18th. The control samples began to decay after 11 days, according to $\mathrm{pH}$ value, while the groups coated solution of Chitosan combined $\beta$-CD-CI inclusion complex was began to corrupt in 20 days. The sensory evaluation results show the control group had beyond the acceptable limit after 13 days; while the groups coated solution of Chitosan combined $\beta$-CD-CI inclusion complex had better shelf life than control group. The total bacterial count value of the groups coated solution of Chitosan combined $\beta$-CD-CI inclusion complex was lower than other groups during the storage. According to those related indexes of fresh beef had reflected the Chitosan film-forming solution combined $\beta$ CD-CI inclusion complex was the most effective in maintaining the quality of the beef, it also prolongs the storage period about 5 7 days compared with the control sample which was the ordinary used.

\section{Acknowledgments}

This work was supported by the National High Technology Research and Development Program of China (863 Program, 2012AA092301), the Innovation Program 
of Shanghai Municipal Education Commission (14YZ120) and the Shanghai Engineering Research Center of Aquatic-Product Processing \& Preservation (11DZ2280300).

\section{References}

[1] ShahidI F, Arachchi JKV, Jeon YJ, Food applications of chitin and chitosans. Trends in Food Science \& Technology, 10 (2), 37-51, 1999.

[2] Nychas, G.J.E., Skandamis, P.N., Tassou, C.C., Koutsoumanis, K., Meat spoilage during distribution. Meat Science, 78, 77-89, 2008.

[3] Cha, S. D., \& Chinnan, M. S. Biopolymer-based antimicrobial packaging: A review. Critical Reviews in Food Science and Nutrition, 44, 223-237, 2004.

[4] Ayana, B., \& Nazan, T. K. Use of antimicrobial methylcellulose films to control Staphylococcus aureus during storage of kasar cheese. Packaging Technology and Science, 22, 461-469, 2009.

[5] Caccioni, D. R. L., Guizzardi, M., Biondi, D. M., Renda, A., \& Ruberto, G. Relationship between volatile components of citrus fruit essential oils and antimicrobial action on Penicillium digitatumand Penicillium italicum. International Journal of Food Microbiology, 43 (1e2), 73e79, 1998.

[6] Linde, J. H., Combrinck, S., Regnier, T. J. C., \& Virijevic, S. Chemical composition and antifungal activity of the essential oils of Lippia rehmannii from South Africa. South African Journal of Botany, 76 (1), 37e42, 2010.

[7] Wolken, W. A., Tramper, J., \& Werf, M. J. Toxicity of terpenes to spores and mycelium of Penicillium digitatum. Biotechnology and Bioengineering, 80 (6), 685e690, 2002.

[8] Belda-Galbis CM, Pina-Pérez MC, Leufvén A, Martínez A. Rodrigo D. Impact assessment of carvacrol and citral effect on Escherichia coli K12 and Listeria innocua growth. Food Control, 33 (2), 536-544, 2013.

[9] Maswal M, Dar AA. Inhibition of citral degradation in an acidic aqueous environment by polyoxyethylene alkylether surfactants. Food chemistry, 138 (4), 2356-2364, 2012.

[10] Delvalle E. Cyclodextrins and their uses: a review. Process Biochemistry, 39 (9), 1033-1046, 2004.

[11] Wang J, Cao Y, Sun B, Wang C. Physicochemical and release characterisation of garlic oil- $\beta$-cyclodextrin inclusion complexes. Food Chemistry, 127 (4), 1680-1685, 2011.

[12] Suman S, Mancini R, Joseph P, Ramanathan R, Konda M, Dady G, Yin S. Chitosan inhibits premature browning in ground beef. Meat science, 88 (3), 512-516, 2011.
[13] Helander I, Nurmiaho-Lassila EL, Ahvenainen R, Rhoades J, Roller S. Chitosan disrupts the barrier properties of the outer membrane of Gram-negative bacteria. International journal of food microbiology, 71 (2), 235-244, 2001.

[14] Darmadji P, Izumimoto M. Effect of chitosan in meat preservation. Meat Science, 38 (2), 243-254, 1994.

[15] Ayala-Zavala JF, Soto-Valdez H, González-León a, ÁlvarezParrilla E, Martín-Belloso O, González-Aguilar GA. Microencapsulation of cinnamon leaf (Cinnamomum zeylanicum) and garlic (Allium sativum) oils in $\beta$-cyclodextrin. Journal of Inclusion Phenomena and Macrocyclic Chemistry, 60 (3-4), 359368, 2008.

[16] Payne et al., K.R. Payne, J.C. Brooks, J.B. Morgan, F.K. Ray The effect of fresh and frozen storage on palatability, oxidative rancidity, and color of modified atmosphere packaged beef steaks Animal science research report, Oklahoma State University, Stillwater, 2002. [Online].

[17] Available: http://www.ansi.okstate.edu/research/research-reports1/2002/2002\%20Payne\%20Research\%20Report.pdf.[ Accessed June 15, 2010].

S.P. Suman, R.A. Mancini, P. Joseph, R. Ramanathan, M.K.R Konda, G. Dady, S. Yin, Packaging-specific influence of chitosan on color stability and lipid oxidation in refrigerated ground beef, Meat Science, 86(4), 994-998, 2010.

[18] Jingyun Duan, Yan Jiang, Gita Cherian, Yanyun Zhao, Effect of combined chitosan-krill oil coating and modified atmosphere packaging on the storability of cold-stored lingcod (Ophiodon elongates) fillets, Food Chemistry, 122 (4), 1035-1042, 2010.

[19] Duan J, Jiang Y, Cherian G, Zhao Y. Effect of combined chitosankrill oil coating and modified atmosphere packaging on the storability of cold-stored lingcod fillets. Food Chemistry, 122 (4), 1035-1042, 2010.

[20] Goulas, A. E., \& Kontominas, M. G. Combined effect of light salting, modified atmosphere packaging and oregano essential oil on the shelf-life of sea bream (Sparus aurata): Biochemical and sensory attributes. Food Chemistry, 100, 287-296, 2007.

[21] Rhys J Jones, Observations on the succession dynamics of lactic acid bacteria populations in chill-stored vacuum-packaged beef, International Journal of Food Microbiology, 90 (3), 273-282, 2004

[22] Rita M Sakala, Hideki Hayashidani, Yukio Kato, Tomoko Hirata, Yuki Makino, Aya Fukushima, Toyomi Yamada, Choji Kaneuchi, Masuo Ogawa, Change in the composition of the microflora on vacuum-packaged beef during chiller storage, International Journal of Food Microbiology, 74 (1-2), 87-99, 2002.

[23] Fereidoon Shahidi, Janak Kamil Vidana Arachchi, You-Jin Jeon, Food applications of chitin and chitosans, Trends in Food Science \& Technology, 10 (2), 37-51, 1999. 